\title{
BMJ Open Association between the level of municipality healthcare services and outcome among acutely older patients in the emergency department: a Danish population-based cohort study
}

\author{
Anette Tanderup, ${ }^{1,2}$ Jesper Ryg, ${ }^{1,3}$ Jens-Ulrik Rosholm, ${ }^{1,3}$ \\ Annmarie Touborg Lassen ${ }^{1,4}$
}

To cite: Tanderup A,

Ryg J, Rosholm J-U, et al. Association between the level of municipality healthcare services and outcome among acutely older patients in the emergency department: a Danish population-based cohort study. BMJ Open 2019;9:e026881. doi:10.1136/ bmjopen-2018-026881

- Prepublication history and additional material for this paper are available online. To view these files, please visit the journal online (http://dx.doi org/10.1136/bmjopen-2018026881).

Received 24 September 2018 Revised 18 December 2018 Accepted 17 January 2019
Check for updates

(C) Author(s) (or their employer(s)) 2019. Re-use permitted under CC BY-NC. No commercial re-use. See rights and permissions. Published by BMJ.

For numbered affiliations see end of article.

Correspondence to

Anette Tanderup;

Anette.tanderup@rsyd.dk

\section{ABSTRACT}

Objectives This study aims to describe the association between use of municipality healthcare services before an emergency department (ED) contact and mortality, hospital reattendance and institutionalisation.

Design Population-based prospective cohort study.

Setting ED of a large university hospital.

Participants All medical patients $\geq 65$ years of age from a single municipality with a first attendance to the ED during a 1-year period (November 2013 to November 2014).

Primary and secondary outcome measures Patients were categorised as independent of home care, dependent of home care or in residential care depending on municipality healthcare before ED contact. Patients were followed 360 days after discharge. Outcomes were postdischarge mortality, hospital reattendance and institutionalisation.

Results A total of 3775 patients were included (55\% women), aged (median (IQR) 78 years (71-85)). At baseline, $48.9 \%$ were independent, $34.9 \%$ received home care and $16.2 \%$ were in residential care. Receiving home care or being in residential care was a strong predictor of mortality, hospital reattendance and institutionalisation. Among patients who were independent, $64.3 \%$ continued being independent up to 360 days after discharge. Even among patients $\geq 85$ years, $35.4 \%$ lived independently in their own house 1 year after ED contact.

Conclusion Prehospital information on municipality healthcare is closely related to patient outcome in older ED patients. It might have the potential to be used in risk stratification and planning of needs of older acute medical patients attending the ED.

\section{INTRODUCTION}

Worldwide the proportion of older people (age 65 years or older) is increasing and it is expected that older patients will comprise an increasing proportion in the emergency departments (EDs). ${ }^{12}$

An ED contact indicates a high-risk situation for older patients. There are several potential poor outcomes following discharge including

\section{Strengths and limitations of this study}

- This population-based cohort study from a Danish municipality was based on data from several Danish national registers.

- A major strength was the complete coverage of a municipality, the complete follow-up and high data quality.

- Home care was registered during delivery making data more realistic.

- The study was a single-centre study which may reduce the generalisability of the results.

- Categorisation of patients according to level of municipality healthcare may not give the true level of dependency.

mortality, ${ }^{3-14}$ hospital reattendance ${ }^{6} \quad 10 \quad 15-18$ and institutionalisation. ${ }^{11} \quad 1920$ Prognostic factors for these outcomes are numerous including increasing age, ${ }^{3-8}$ 11-14 number of drugs, ${ }^{10}$ comorbidity, ${ }^{4}{ }^{712}$ male sex ${ }^{7-9} 11$ previous hospitalisations, ${ }^{10}{ }^{12}$ length of stay, ${ }^{4}$ functional disability ${ }^{5}$ 7-11 1419 and being a nursing home resident prior to admission. ${ }^{5} 14$

Knowledge of prognostic factors is useful to identify patients at high risk of poor outcomes for whom targeted intervention and treatment may be indicated.

In daily clinical ED practice where the staff is handling a high number of patients, identification of special prognostic factors in the management and treatment planning of the older patients might stay unrecognised. Assessment of patients' social history including use of other healthcare services is a part of daily clinical work, but evidence for its prognostic usefulness is limited.

Frailty is a health state with increased vulnerability to stressors and identification of frailty has proved to be an important 
prognostic factor. ${ }^{21}$ Use of healthcare services like home care is a part of the two most validated frailty screening tools because it is assumed that it grants relevant information and help guide treatment and care ${ }^{2223}$ However, the concept of frailty and geriatric emergency medicine are not well implemented in the ED and it is often restricted to be used by geriatricians. ${ }^{24}$

As many older patients are often dependent on municipality healthcare services like home care,$^{25}$ it is possible that systematic knowledge of the patients' dependency of municipality healthcare services has a potential to add information, that is, easily accessible, in the assessment of risk and prognosis in the ED.

The aim of this study was to assess the association between dependency of municipality healthcare services prior to ED contact and the risk of mortality, rehospitalisation and institutionalisation in 360 days after discharge in patients $\geq 65$ years attending the ED.

\section{METHOD \\ Participants}

We included all patients 65 years or older living in Odense municipality with a first acute medical contact to the ED of Odense University Hospital, Denmark, from 1 November 2013 to 31 October 2014. We excluded patients dead on arrival to the ED, patients without a Danish personal identification number and patients residing outside Odense Municipality at the time of index contact.

Data on the same patients have been used in a previous study. $^{26}$

\section{Study design and setting}

We conducted a population-based cohort study with follow-up 360 days after an acute medical hospital contact.
Odense University Hospital is a 1000-bed university teaching hospital with all specialties present. The ED provides 24 hours acute medical care and serves a mixed rural-urban primary catchment area of 288200 persons including Odense municipality, which has a population of 168731 adult citizens with $20.0 \%$ being 65 years or older. ${ }^{27}$ It is the only ED in this area. Patients are referred from primary care or arrive by ambulance emergency call. The ED receives all acute patients except patients with prehospital identified cardiogenic disease, ongoing nephrogenic or oncological treatment. At arrival, all patients are assigned to a specialty track and an urgency category based on main complaint and vital signs. ${ }^{28}$

The Danish healthcare system is tax funded and provides free healthcare for all residents. The primary care services are well established and free of charge for the patients. The municipalities are responsible for delivery of any kind of home care services to older and disabled people. Each municipality delivers home care consisting of general nursing care and care to support activities of daily living (ADL). The type and amount of home care are based on an individual plan laid down in collaboration with a special educated nurse and changes are adjusted continuously with 1-day notice. Staff does on-location registrations of time and task. The data are automatically transferred to a personal electronic citizen record. Furthermore, the municipality administrates residential care institutions like rehabilitation homes and nursing homes.

\section{Data source}

Data were assembled from the data sources seen in table 1.

The Odense University Pharmacoepidemiological Database is a prescription database
Table 1 Description of data sources

Data source

The Danish Civil Registration System (CRS)

The Danish National Patient Register (NPR)

\section{Description}

Since 1968 the Danish CRS has assigned a unique 10-digit civil personal registry number to each Danish citizen at birth and to residents on immigration.

The CRS covers data on births, deaths, migration, municipality and marital status. ${ }^{30}$ The unique civil registry number enables accurate linkage of information from different data sources on an individual level.

Since 1977 the Danish NPR has registered all hospital admissions and since 1995 also all ED visits. ${ }^{50}$

Data are assembled regarding the date of admission and discharge and admission department.

The electronic hospital record and the emergency department (ED)-logistic system

Odense University Pharmacoepidemiological Database (OPED)

The Municipality Citizen Record
All hospital data from each patient are registered and stored in the electronic hospital record and the logistic tool used in the ED.

OPED is a prescription database. It covers the region of Southern Denmark including the municipality of Odense. Information on dispensed prescriptions is reported on an individual basis from community pharmacies to OPED. Only drugs that are reimbursed are covered. ${ }^{33}$

All data on kind and amount of home care and resident type are registered in The Municipality Citizen Record on an individual level. When residents are in residential care, it is registered as such. 


\section{Data variables}

If a patient had more medical acute ED contacts in the study period, only the first contact was included as the index contact. The primary date of contact defined the index date. Index contact date and urgency category at arrival were collected from the patient health record and the ED electronic logistic tool. Urgency category was defined from the initial triage. ${ }^{29}$ In the present study, urgency categories were dived in two predefined urgency categories: level 1 and 2 as 'urgent' and level 3 and 4 as 'less urgent'.

Data on patients' status on receiving home care or being in residential care were retrieved from The Municipality Citizen Record. Patients were subdivided in three groups according to the level of dependency on municipality healthcare the last 30 days prior to the index date: 'Residential care' defined as one or more days at a nursing home or a rehabilitation home, 'Dependent on home care' defined as receiving any municipality home care and 'Independent' defined as not receiving any municipality home care the preceding 30 days. Patients could only be in one category and it was prioritised as: residential care, dependency of home care or independent of home.

Data on birth, migration, vital status, municipality of residence and marital status were retrieved from the Danish Civil Registration System. ${ }^{30}$ We categorised patients as being alone if they were single, divorced, widower or widow.

Based on registration in the Danish National Patient Register, the length of stay was calculated from the date of index contact to the end of hospitalisation. Contacts were classified as ED visits if patients were not admitted to the hospital. All other contacts were classified as admissions and dived in two categories: $<48$ hours admission or $\geq 48$ hours admission.

Comorbidity was described based on Charlson Comorbidity Index identified by hospital discharge diagnoses from the previous 10 years. ${ }^{31} 32$

The number of medications with different Anatomical Therapeutic Chemical (ACT) codes (fourth level, chemical subgroup) reimbursed within 3 months prior to the index contact was used to calculate the number of medications at index contact. 3334

\section{Outcome variables}

Outcome variables were mortality, hospital reattendance and institutionalisation. All outcome variables were assessed at 30 and 360 days following discharge. The time started from the day of discharge. The proportion of patients that had been in residential care one or more days in the 360 days period after discharge, the proportion of patients that had received any home care (dependent on municipality home care) one or more days in the 360 days period after discharge and the proportion of patients that did not receive any home care (independent on municipality home care) all 360 days after discharge were measured.

\section{Data analysis and statistical methods}

The distribution of patients in age categories, gender, Charlson Comorbidity Index, contact category (ED visit or admission), length of stay (in days) and urgency category according to the level of dependency within the 30 days prior to ED contact were presented as total and proportions or as medians with IQR. Only medians and (IQR) were calculated due to the skewness of the data distributions. $\chi^{2}$ test was used to test the significance of differences between proportions in categorical data.

All-cause mortality proportions were calculated at 30 days and 360 days after discharge. Risk factors were evaluated by Cox regression analysis and presented as unadjusted and adjusted HRs with 95\% CIs at 30 days and 360 days after discharge. Level of municipality healthcare the month before index contact, age (as a continuous variable), gender, Charlson Comorbidity Index, number of medications, being alone, length of stay and urgency category (as categorical variables) were used as independent variables.

Risk factors for hospital reattendance and for institutionalisation 30 days and 360 days after discharge were analysed using competing risks methodology with hospital reattendance and residential care analysed separately as the event of interest and death due to any cause as the competing event.

Level of municipality healthcare the month before index contact, age, gender, Charlson Comorbidity Index, number of medications, being alone, length of stay and urgency category were used as independent variables.

Cumulative competing risk curves for acute hospital reattendance and institutionalisation were calculated and presented.

The proportion of patients being independent, dependent on home care or living in residential care 30 days and 360 days after discharge stratified by level of municipality healthcare the month before was calculated.

Variance inflating factors were calculated to evaluate collinearity.

No data were missing on mortality, municipality healthcare or hospital reattendance. Data on being alone were missing in 43 patients and data on urgency category were missing in 53 patients. Sensitivity analyses were done with missing data replaced by 'being alone' or 'not being alone' for alone status and 'urgent' or 'less urgent' for urgency category.

Follow-up was complete for all patients.

All calculations were performed using Stata Release V.15.0 (StataCorp).

The reporting of this study conforms to the Strengthening the Reporting of Observational Studies in Epidemiology statement and the checklist was completed. ${ }^{35}$

\section{Patient and public involvement}

Patients and/or public were not involved in the development, design, recruitment or conduct of the study. 


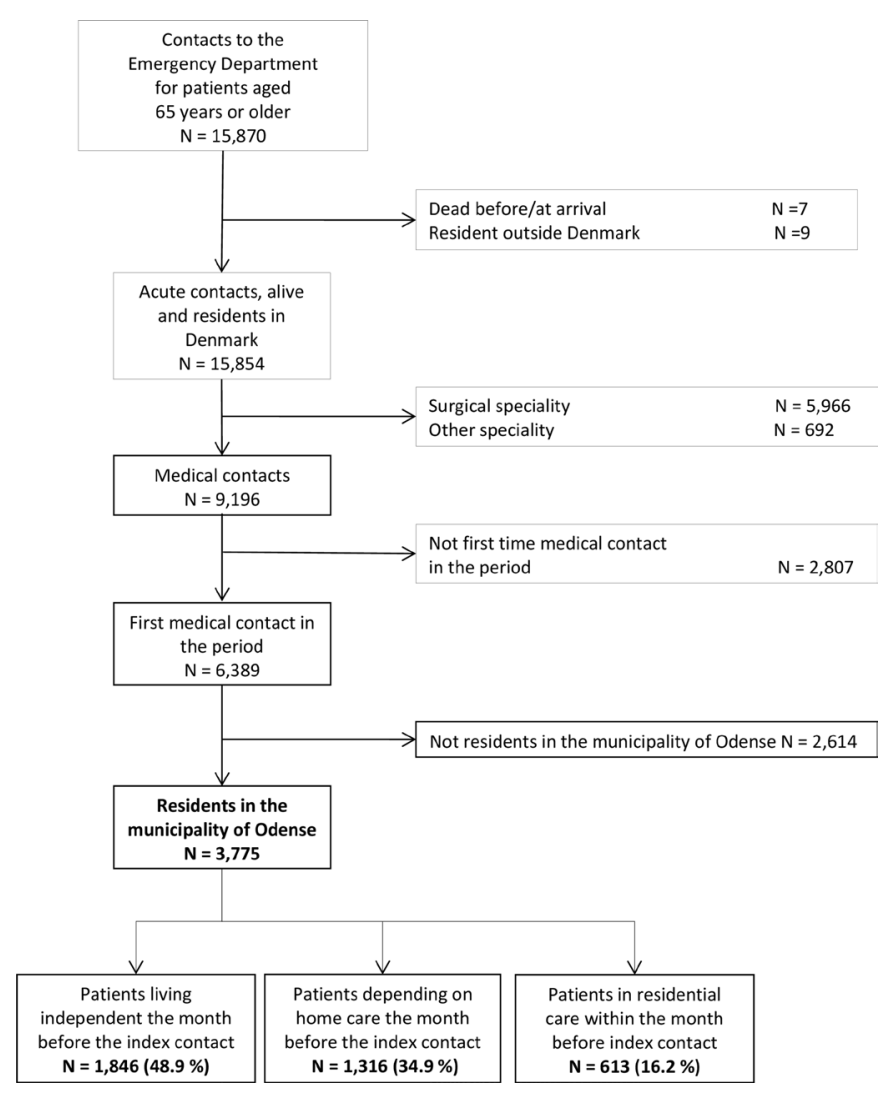

Figure 1 Flow chart of patients included in the study period.

\section{RESULTS}

\section{Participants}

Among the 6389 first-time medical contacts for older patients to the ED in the study period, 3775 patients were citizens in Odense municipality and included in the study (figure 1).

Median (IQR) age of the included patients was 78 years (71-85), 55\% were female. Median Charlson Comorbidity Index was $1(0-3)$, the median number of medications at index contact was 5 (3-8) and $38.8 \%$ were categorised as urgent at arrival (table 2).

Within the month before index contact, $48.9 \%$ of the 3775 patients were independent, $34.9 \%$ were dependent on home care (median days 18 days (3-30)) with $37.5 \%$ of these receiving home care all days and $16.2 \%$ were in residential care one or more days (median days 30 (30-30)) with $81.1 \%$ in residential care all 30 days (figure 1 ).

Table 2 describes the characteristics of the 3775 patients displayed by level of municipality healthcare the month before index ED contact. Patients who were independent before the ED contact were younger (median age 74 (69-79)), the majority was not alone $(59.6 \%)$, had less comorbidity (median Charlson Comorbidity Index $1(0-2)$ ) and took fewer medications (median $4(2-7)$ ) than patients dependent on home care and patients in residential care. In the groups of patients receiving home care and patients in residential care the month before the index contact, no significant differences were seen in age, comorbidity or the number of medications taking on a regular basis.
The urgency level at arrival to the ED did not vary between the three groups, but patients in residential care were more impaired in their conscious level (data not displayed). Significantly less of the independent patients were admitted and the admissions were shorter (table 2) $(\mathrm{p}<0.001)$.

\section{Outcome}

Mortality

In-hospital mortality was $4.0 \%$ in independent patients, $9.4 \%$ in dependent patients and $9.5 \%$ in patients in residential care (table 2) $(\mathrm{p}<0.001)$.

Among patients discharged alive a total of $4.9 \%$ died within 30 days after discharge and 20\% within 360 days. In our study, $13.6 \%$ of those independent of municipality home care in the month before the index contact-and discharged alive from hospital-were dead within 1 year after discharge. Whereas $35 \%$ and $43 \%$ of those dependent on home care or in residential care the month before index contact-and discharged alive-were dead within 1 year after discharge, respectively $(\mathrm{p}<0.001)$.

Hospital reattendance and institutionalisation

Of the 3519 patients discharged alive $44.6 \%$ had reattended the hospital within 360 days.

We found that $12 \%$ of patients receiving home care before ED contact were or had been in residential care within 30 days after discharge. Only $3 \%$ of patients who were independent were or had been in residential care within 30 days after discharge.

\section{Independent}

Stratifying for age categories, figure 2 displays the proportion of patients discharged alive who died, stayed in residential care (any day), were dependent on home care (any day) or were independent (all days) in the 360 days period after discharge in relation to level of municipality healthcare the 30 days before ED contact.

In patients $\geq 85$ years of age who were independent before ED contact more than $35 \%$ were still independent all 360 after discharge and about $70 \%$ still lived in their own home with or without home care.

\section{Prognostic factors}

In the multiple variable analysis, we found that receiving home care doubled the risk of mortality within 360 days (HR 2.07, 95\% CI 1.68 to 2.56) and residential care tripled the risk (HR 3.03, 95\% CI 2.39 to 3.85). Male sex, age, comorbidity and index admission lasting over 48 hours were also independent predictors of mortality (table 3 ).

Likewise, receiving home care increased the risk of reattendance to the ED. Within 30 days after discharge (sub-HR (SHR) 1.46, 95\% CI 1.22 to 1.64 ) and within 360 days after discharge (SHR 1.16, 95\% CI 1.01 to 1.32). Residential care before index contact seemed to be a protective factor for hospital reattendance within 360 days after discharge (SHR 0.84, 95\% CI 0.70 to 1.01) (table 4). Cumulative competing risk curve of acute hospital reattendance displayed by level of municipality healthcare 
Table 2 Baseline characteristics of the whole study population stratified according to level of dependency of home care within the month prior to index contact

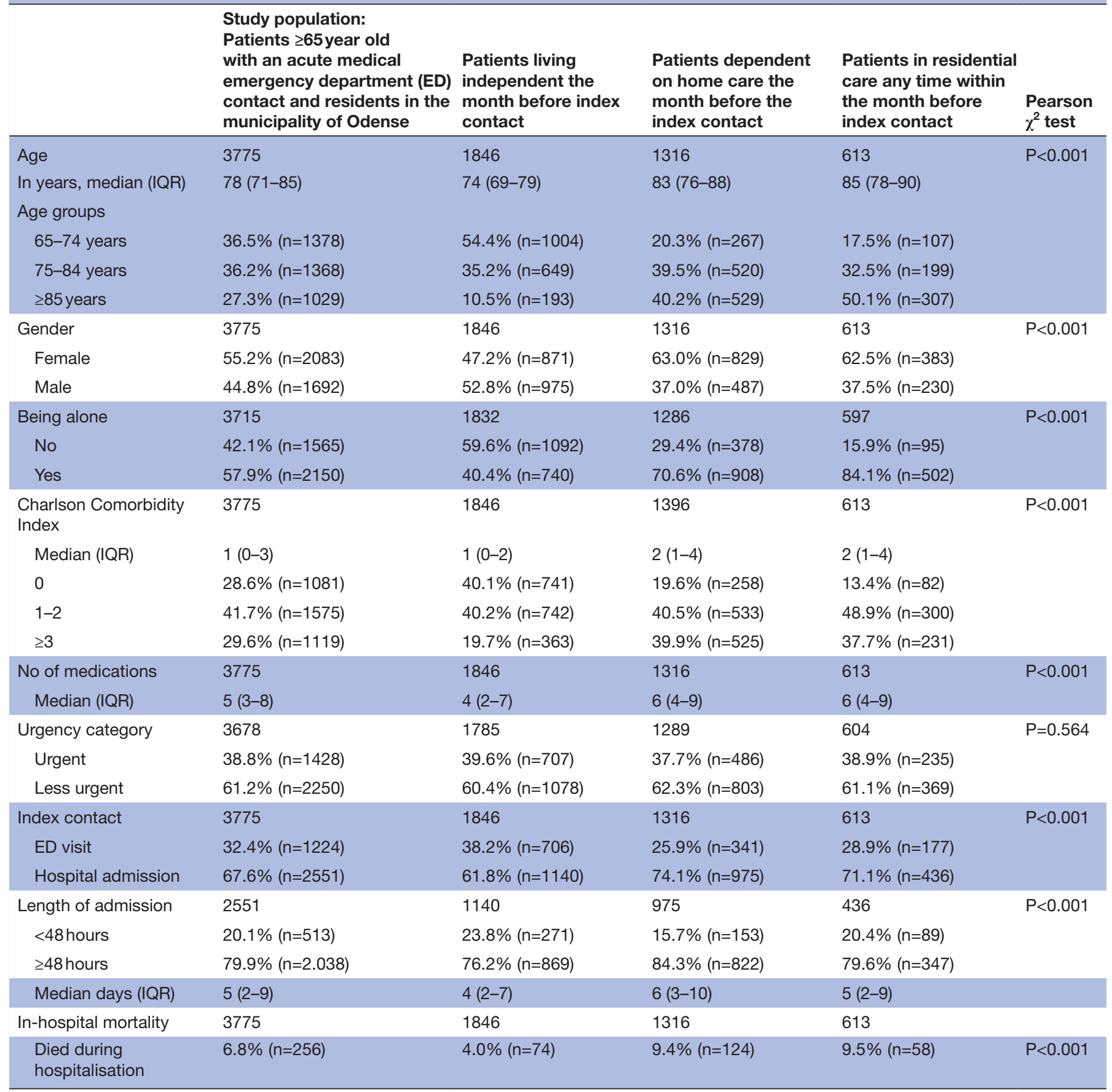

Data are presented as number of patients (n), proportions (\%) and median (IQR).

before initial ED contact are displayed in online supplementary A.

For independent patients and dependent patients, the adjusted SHR for residential care 360 days after discharge were three times higher for patients receiving home care (SHR 3.26, 95\% CI 2.34 to 4.54) (table 5). Cumulative competing risk curve of residential care placement after discharge from the ED displayed by level of municipality healthcare 30 days before contact to the ED is displayed in online supplementary B.
Sensitivity analysis for missing data did not show any significant differences for HR or SHR.

\section{DISCUSSION}

We found that the level of municipality healthcare dependency is a powerful predictor of postdischarge mortality, hospital reattendance and institutionalisation for older medical ED patients. If you are independent of municipality healthcare the month before ED contact, there is 


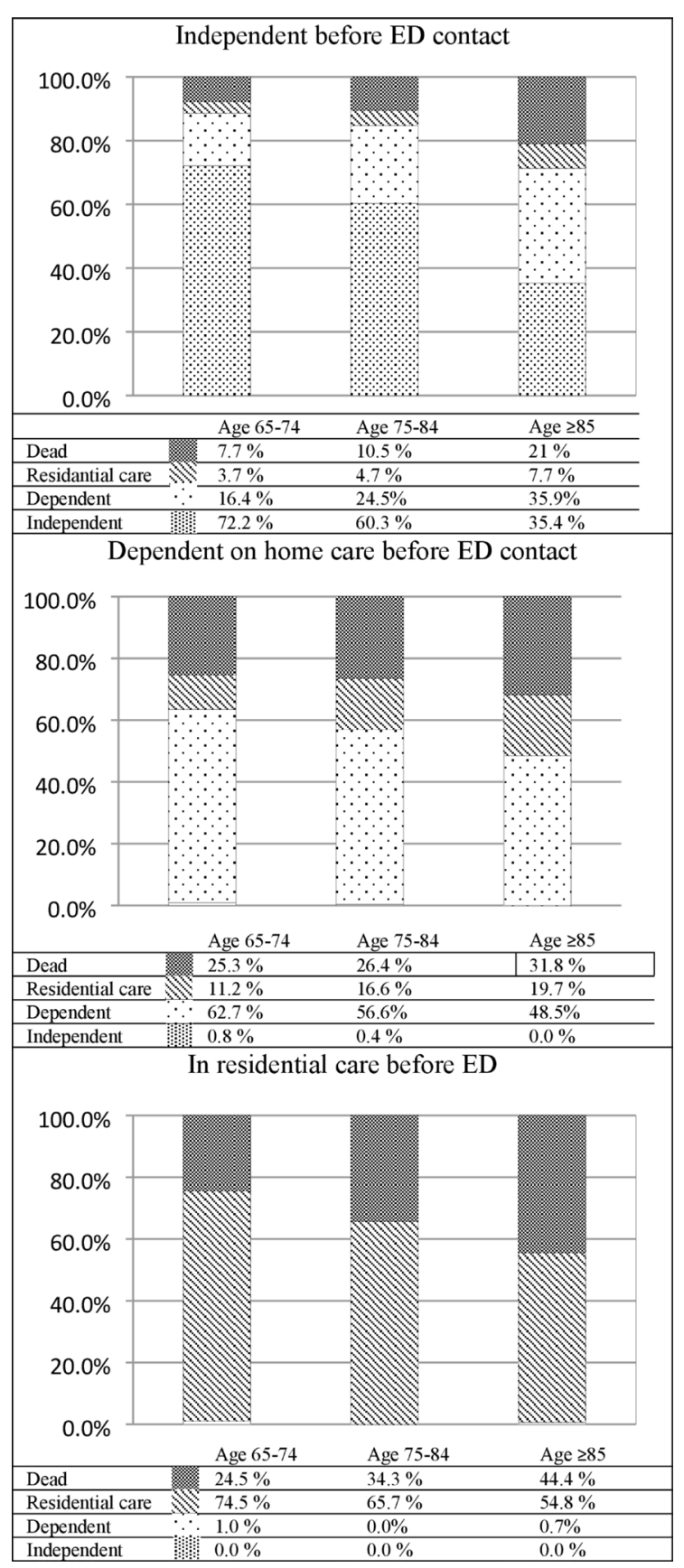

Figure 2 Stratifying for age categories, the proportion of patients discharged alive who died, stayed in residential care, received home care or lived independent in the 360 days period after discharge in relation to level of municipality healthcare the 30 days before index ED contact. ED, emergency department.

a good chance to be alive and living independent—or at least in your own home-1 year after discharge, even among the oldest patients.

Taking a social history is a part of patient assessment, but the evidence for the prognostic usefulness has been limited. In our study, we showed that information about level of dependency from municipality healthcare is a strong prognostic factor. This emphasises how important it is to continue asking patients about their need for help. ${ }^{36}$ Additionally, in the presence of cognitive impairment, history taking may be difficult and time consuming. Applying the information directly from the municipality healthcare record to the hospital record would help overcome some of the difficulties assessing the social history.

We found an overall mortality of $20 \%, 360$ days after discharge. One-year mortality reported in other studies varies from $7 \%$ to $30 \% .^{56811}$ They differed from our setting by including in-hospital mortality or only hospital admissions ${ }^{58}$ and different median ages. ${ }^{511}$ Male sex, age and comorbidity were also reported in other studies as independent predictors of mortality. ${ }^{56811}$

Like other studies, we found residential care to be a predictor of mortality. ${ }^{514}$ There is conflicting evidence of the predictive value of residential care as a risk for hospital reattendance. One study found residential care to decrease the risk of readmission within 30 days. ${ }^{37}$ Others found an increased risk. ${ }^{638}{ }^{39}$ Not all of the reported findings were statistical significant and none of the studies used competing risk methodology. We found residential care to be associated with an increased risk of reattendance within 30 days, and a non-statistic decrease of reattendance within 360 using a competing risk method.

Dependency of home care as a predictor of poor outcome has not been intensively investigated. Increased risk of hospital reattendance has been reported. ${ }^{17} 39$ Home care dependency reflects the lack of capability to withhold ADL due to restrains in psychical, cognitive, mental and social capacity. Several studies have shown an increased risk of mortality, hospital reattendance and institutionalisation among older patients with functional and cognitive impairment. ${ }^{5} 79111940-42$ Studies vary in follow-up time, the way of measuring functional disability and measurement time.

One of the known major frailty models is the accumulation of deficits model. ${ }^{43}$ It counts the number of deficits found/seen in a patient, for example, functional disability, comorbidity and cognitive impairment. It has been validated to successfully predict poor outcome in numerous studies. ${ }^{44-46}$ A more clinical and ED useful version has been developed. ${ }^{23}$ The Clinical Frailty Scale (CFS) has also been validated in the ED to predict poor outcome. ${ }^{47} 48$ The CFS is largely based on the required help with ADL. For example, on the 1-9 point frailty scale, a mildly frail patient (point 5) is in need of help with medications, domestic tasks and shopping, whereas a severely frail patient is completely dependent in all areas of ADL. In our study, we solely distinguished between whether a person received municipality home care, were in residential care or were independent of municipality home care. More detailed information on what activities of ADL patients were assisted with and what kind of nursing care and domestic help they received would also be possible to extract in future studies. Additionally, it would also be important to include care and help delivered by family or friends. We were not able to include this in our present study.

Knowledge of powerful risk factors, as receiving home care, may be used in the design of specialist services for 


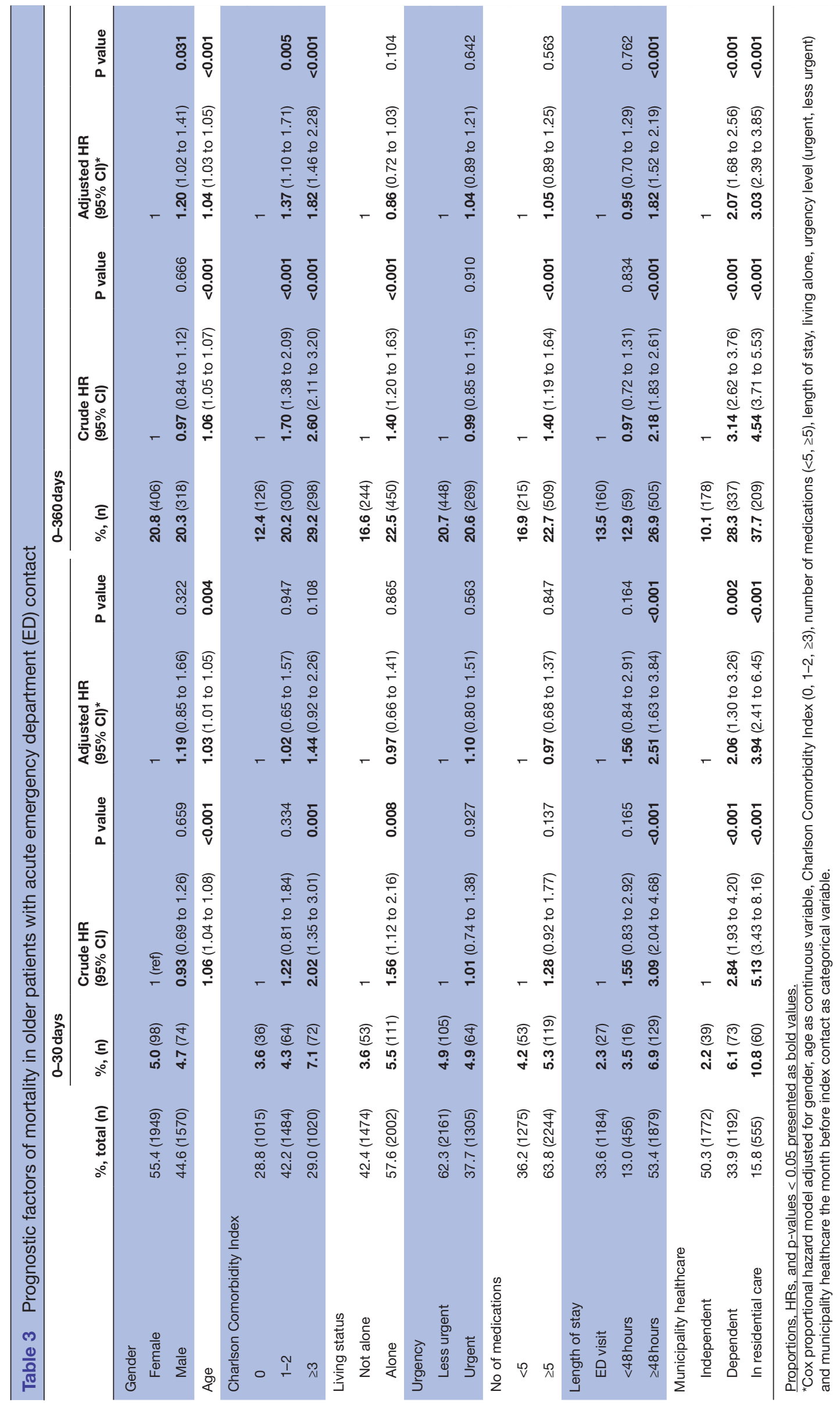




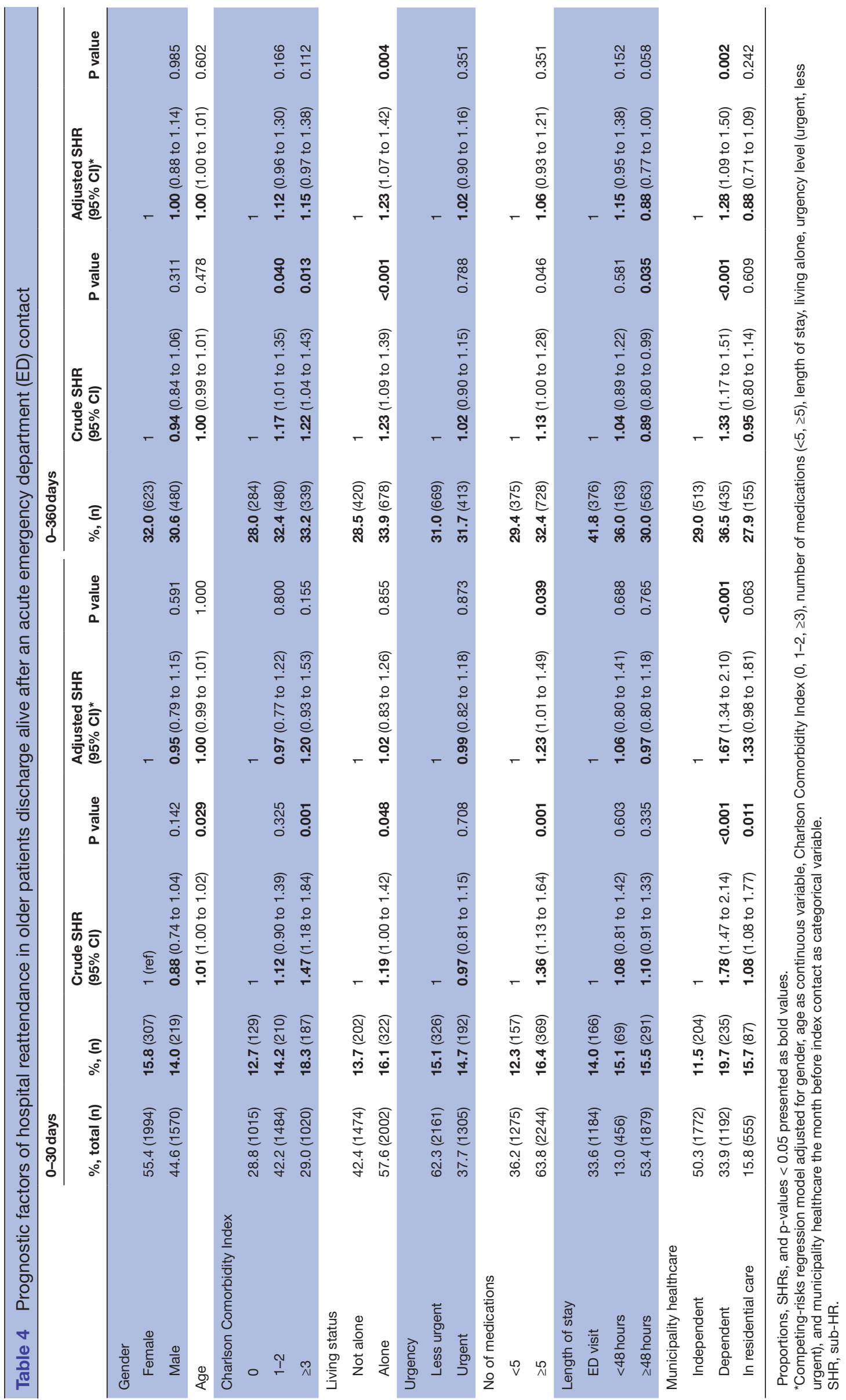

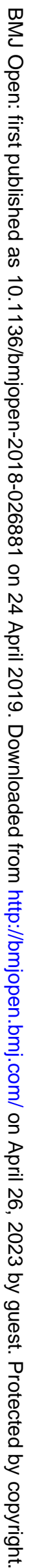




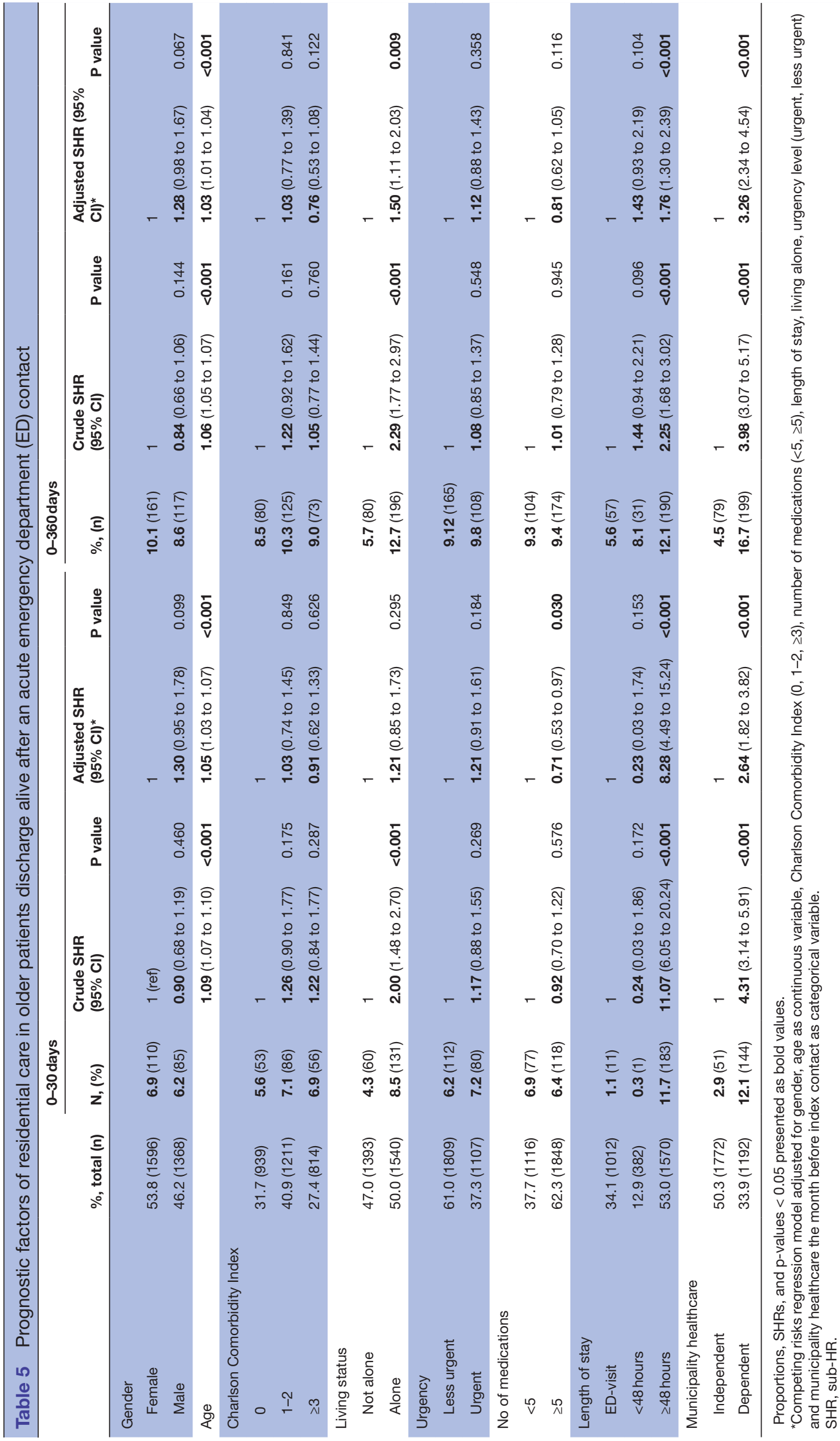


older people at risk. But, it is also important to focus on the patients who do not suffer a poor outcome as mortality, reattendance or institutionalisation. We showed that living independent before an ED contact was a stronger predictor of postdischarge independent living than age. Of course, it might be that these patients actually received some kind of special service, like geriatric attendance and therefore might had a better prognosis, but no significant difference was seen in the allocation to medical specialty among the patients age $\geq 85$ years of age, living independent at ED contact and still living independent after 360 days $(35.4 \%)$ and the rest of the patients.

Another important aspect to consider is age and treatment. In some situations, there is a predominant reluctance towards treatment of the very old patients and ageism still exists among ED—and other-doctors. ${ }^{49}$ As increasing age is often associated with multimorbidity, functional and cognitive impairment, it is correct that age is often associated with poor outcome. However, we found that even among the oldest medical ED patients, their prognosis is very good if they have been able to manage without home care at the arrival to the ED. It, therefore, seems important to include information on level of municipality healthcare to identify those with good chances of survival and maintaining independent living.

\section{Limitations and strengths}

The strengths of this study were the large sample size, and the accurate linkage between healthcare population-based registries allowing complete follow-up. To minimise bias, we included all consecutive medical hospital contacts, the proportion of missing data was very low, sensitivity analysis was done and follow-up was complete. We were able to collect data on all hospital reattendance in all Danish hospital and it was possible to follow each individual patient throughout the study period. Registration of time and type of municipality home care delivered was done during the planned visits, giving data a large conformity with the actual delivered home care and not just what was intended to be delivered.

Our study had some limitations. First, it is a Danish single-centre study and should be interpreted as such, even though the described system for hospital attendance and home care is quite uniform across the country. Second, categorisation of patients not receiving home care as 'independent' could be misleading. They might actually be in need of home care or have a healthy spouse taking care of them. Third, the Charlson Comorbidity Index at ED contact was calculated from information on previously discharge diagnosis, implying that for a given comorbidity to be recognised it had to require hospitalisation with coding for the comorbidity leading to risk of under-reporting. However, it has been shown that the validity of using Danish National health registers to calculate Charlson Comorbidity Index is good. ${ }^{32}$ Finally, several of the covariate estimates changed direction during the modelling process which suggests collinearity issues or possible effect modification in the multiple variables and the result has to be interpreted with this in mind. The mean variance inflation factor was 2.88 . All of the individual variance inflation factors were below 10 , suggesting limited collinearity.

\section{CONCLUSION}

We found that the degree of dependency of municipality healthcare the last month before ED contact was a strong prognostic predictor of mortality, reattendance and institutionalisation. We also found that even among the oldest patients not receiving home care, there is a good chance that they will still be alive and living independent of home care 1 year after discharge. The ED, with its high patient turnover, limited time, and focus on urgent problems, may not be an appropriate place to implement time-consuming assessments of functional impairment and frailty. However, information on home care use and residential care before ED contact is simple and easy add-on information to the patients social history and might have the potential to be used in risk stratification and planning of needs of older acute medical patients attending the ED.

\section{Author affiliations}

${ }^{1}$ Department of Clinical Research, University of Southern Denmark, Odense, Denmark

${ }^{2}$ OPEN, Odense Patient Data Explorative Network, Odense University Hospital,

Odense, Denmark

${ }^{3}$ Department of Geriatric Medicine, Odense University Hospital, Odense, Denmark ${ }^{4}$ Department of Emergency Medicine, Odense University Hospital, Odense, Denmark

Acknowledgements We would like to thank Niels Ibsgaard Agerbek (Odense University Hospital) and Oskar Bak (Odense municipality) for professional help with data extraction.

Contributors All authors participated in the design of the study. AT performed the statistical analyses in a dialogue with ATL, JR and J-UR. AT wrote the manuscript. All authors were involved in the interpretation of data and the critical revision of the manuscript. AT had the primary responsibility for the final content. All authors read and approved the final manuscript.

Funding This study was supported by funding from the Odense University Hospital, the Faculty of Health Science at University of Southern Denmark, the Danish National Innovation Foundation, the Velux Foundation, and 'Trygfonden'.

Competing interests None declared.

Patient consent for publication Not required.

Ethics approval The study was approved by the Danish Data Protection Agency (J No 14/19990) and the National Committee on Health Research Ethics (Project-ID S-20140031).

Provenance and peer review Not commissioned; externally peer reviewed.

Data sharing statement Due to the Danish Law on personal data, we are not allowed to share data in a public dataset. Access to data from the Danish Health Data Authority requires approval from the Danish Data Protection Agency: https:// www.datatilsynet.dk/english/the-danish-data-protection-agency/introduction-tothe-danish-data-protection-agency/. For access and sharing of data and materials please contact the corresponding author or the Research Service at the Department of Clinical Research, University of Southern Denmark and we will help you with the process and following provide access to the dataset.

Open access This is an open access article distributed in accordance with the Creative Commons Attribution Non Commercial (CC BY-NC 4.0) license, which permits others to distribute, remix, adapt, build upon this work non-commercially, and license their derivative works on different terms, provided the original work is 
properly cited, appropriate credit is given, any changes made indicated, and the use is non-commercial. See: http://creativecommons.org/licenses/by-nc/4.0/.

\section{REFERENCES}

1. Aminzadeh F, Dalziel WB. Older adults in the emergency department: a systematic review of patterns of use, adverse outcomes, and effectiveness of interventions. Ann Emerg Med 2002;39:238-47.

2. Organization WH. 10 facts on ageing and health. 2017 (Cited 27 Feb 2018).

3. Fløjstrup M, Henriksen DP, Brabrand M. An acute hospital admission greatly increases one year mortality - Getting sick and ending up in hospital is bad for you: A multicentre retrospective cohort study. Eur J Intern Med 2017; 45:5-7.

4. Levine SK, Sachs GA, Jin L, et al. A prognostic model for 1-year mortality in older adults after hospital discharge. Am J Med 2007:120:455-60.

5. Kellett J, Rasool S, McLoughlin B. Prediction of mortality 1 year after hospital admission. QJM 2012;105:847-53.

6. Kennelly SP, Drumm B, Coughlan T, et al. Characteristics and outcomes of older persons attending the emergency department: a retrospective cohort study. QJM 2014;107:977-87.

7. Matzen LE, Jepsen DB, Ryg J, et al. Functional level at admission is a predictor of survival in older patients admitted to an acute geriatric unit. BMC Geriatr 2012;12:32.

8. Clark D, Armstrong M, Allan A, et al. Imminence of death among hospital inpatients: prevalent cohort study. Palliat Med 2014;28:474-9.

9. Walter LC, Brand RJ, Counsell SR, et al. Development and validation of a prognostic index for 1-year mortality in older adults after hospitalization. JAMA 2001;285:2987-94.

10. Rosted E, Schultz M, Dynesen H, et al. The Identification of Seniors at Risk screening tool is useful for predicting acute readmissions. Dan Med J 2014;61:A4828.

11. Jónsson PV, Noro A, Finne-Soveri $\mathrm{H}$, et al. Admission profile is predictive of outcome in acute hospital care. Aging Clin Exp Res 2008;20:533-9.

12. Klausen $\mathrm{HH}$, Petersen $\mathrm{J}$, Bandholm $\mathrm{T}$, et al. Association between routine laboratory tests and long-term mortality among acutely admitted older medical patients: a cohort study. BMC Geriatr 2017;17:62

13. Hofman SE, Lucke JA, Heim N, et al. Prediction of 90-day mortality in older patients after discharge from an emergency department: a retrospective follow-up study. BMC Emerg Med 2016;16:26.

14. Kellett J, Deane B. The Simple Clinical Score predicts mortality for 30 days after admission to an acute medical unit. QJM 2006;99:771-81.

15. García-Pérez L, Linertová R, Lorenzo-Riera A, et al. Risk factors for hospital readmissions in elderly patients: a systematic review. QJM 2011; 104:639-51.

16. Sona A, Maggiani G, Astengo M, et al. Determinants of recourse to hospital treatment in the elderly. Eur $J$ Public Health 2012;22:76-80.

17. Deschodt $M$, Devriendt $E$ Sabbe $M$, et al. Characteristics of older adults admitted to the emergency department (ED) and their risk factors for ED readmission based on comprehensive geriatric assessment: a prospective cohort study. BMC Geriatr 2015;15:54.

18. Jencks SF, Williams MV, Coleman EA. Rehospitalizations among patients in the Medicare fee-for-service program. N Engl J Med 2009:360:1418-28.

19. Covinsky KE, Justice AC, Rosenthal GE, et al. Measuring prognosis and case mix in hospitalized elders. The importance of functional status. J Gen Intern Med 1997;12:203-8.

20. Luppa M, Luck T, Weyerer S, et al. Prediction of institutionalization in the elderly. A systematic review. Age Ageing 2010;39:31-8.

21. Kojima G, lliffe S, Walters K. Frailty index as a predictor of mortality: a systematic review and meta-analysis. Age Ageing 2018:47:193-200.

22. Salvi F, Morichi V, Grilli A, et al. Screening for frailty in elderly emergency department patients by using the Identification of Seniors At Risk (ISAR). J Nutr Health Aging 2012;16:313-8.

23. Rockwood K, Song X, MacKnight $\mathrm{C}$, et al. A global clinical measure of fitness and frailty in elderly people. CMAJ 2005;173:489-95.
24. McNamara RM, Rousseau E, Sanders AB. Geriatric emergency medicine: a survey of practicing emergency physicians. Ann Emerg Med 1992;21:796-801.

25. Young HM. Challenges and solutions for care of frail older adults. Online J Issues Nurs 2003;8:5.

26. Tanderup A, Lassen AT, Rosholm JU, et al. Disability and morbidity among older patients in the emergency department: a Danish population-based cohort study. BMJ Open 2018;8:e023803.

27. Danmarks Statestik. 2017. www.statistikbanken.dk/BY2 (Cited 14 Mar 2018).

28. Lindberg S $\varnothing$, Lerche la Cour J, Folkestad L, et al. The use of triage in Danish emergency departments. Dan Med Bull 2011;58:A4301.

29. Castrén $M$, Lethvall $S$, Castrén $M$. The validity of the triage system ADAPT. Scand J Trauma Resusc Emerg Med 2010;18:36.

30. Schmidt M, Pedersen L, Sørensen HT. The Danish Civil Registration System as a tool in epidemiology. Eur J Epidemiol 2014;29:541-9.

31. Charlson ME, Pompei P, Ales KL, et al. A new method of classifying prognostic comorbidity in longitudinal studies: development and validation. J Chronic Dis 1987;40:373-83.

32. Thygesen SK, Christiansen CF, Christensen S, et al. The predictive value of ICD-10 diagnostic coding used to assess Charlson comorbidity index conditions in the population-based Danish National Registry of Patients. BMC Med Res Methodol 2011;11:83.

33. Hallas J, Hellfritzsch M, Rix M, et al. Odense pharmacoepidemiological database: a review of use and content. Basic Clin Pharmacol Toxicol 2017;120:419-25.

34. Methodology WCCfDS. Structure and principles. 2011. https://www. whocc.no/atc/structure and principles/ (Cited 26 Dec 2017).

35. Vandenbroucke JP, von Elm E, Altman DG, et al. Strengthening the Reporting of Observational Studies in Epidemiology (STROBE): explanation and elaboration. Int J Surg 2014;12:1500-24.

36. Anderson RA, Schiedermayer D. The social history matters!. Acad Med 2010;85:1103.

37. Comette P, D'Hoore W, Malhomme B, et al. Differential risk factors for early and later hospital readmission of older patients. Aging Clin Exp Res 2005;17:322-8.

38. McCusker J, Bellavance F, Cardin S, et al. Prediction of hospital utilization among elderly patients during the 6 months after an emergency department visit. Ann Emerg Med 2000;36:438-45.

39. Rasmussen MG, Ravn P, Molsted S, et al. Readmission to hospital of medical patients - a cohort study. Eur J Intern Med 2017;46:19-24.

40. Rudberg MA, Sager MA, Zhang J. Risk factors for nursing home use after hospitalization for medical illness. J Gerontol A Biol Sci Med Sci 1996;51:M189-94.

41. Fortinsky RH, Covinsky KE, Palmer RM, et al. Effects of functional status changes before and during hospitalization on nursing home admission of older adults. J Gerontol A Biol Sci Med Sci 1999;54:M521-6.

42. Bierman AS. Functional status: the six vital sign. J Gen Intern Med 2001;16:785-6.

43. Rockwood K, Mitnitski A. Frailty in relation to the accumulation of deficits. J Gerontol A Biol Sci Med Sci 2007;62:722-7.

44. Rockwood K, Mitnitski A, Song X, et al. Long-term risks of death and institutionalization of elderly people in relation to deficit accumulation at age 70. J Am Geriatr Soc 2006;54:975-9.

45. Rockwood K, Andrew M, Mitnitski A. A comparison of two approaches to measuring frailty in elderly people. J Gerontol A Bio Sci Med Sci 2007;62:738-43.

46. Jones D, Song X, Mitnitski A, et al. Evaluation of a frailty index based on a comprehensive geriatric assessment in a population based study of elderly Canadians. Aging Clin Exp Res 2005;17:465-71.

47. Wallis SJ, Wall J, Biram RW, et al. Association of the clinical frailty scale with hospital outcomes. QJM 2015;108:943-9.

48. Basic D, Shanley C. Frailty in an older inpatient population: using the clinical frailty scale to predict patient outcomes. J Aging Health 2015;27:670-85.

49. Kydd A, Fleming A. Ageism and age discrimination in health care: fact or fiction? A narrative review of the literature. Maturitas 2015;81:432-8.

50. Schmidt M, Schmidt SA, Sandegaard JL, et al. The Danish National Patient Registry: a review of content, data quality, and research potential. Clin Epidemiol 2015;7:449-90. 